\title{
GAMBARAN UMUM FEEDING PRACTICES YANG DITERAPKAN ORANG TUA PADA ANAK PICKY EATING
}

\author{
PEER SUPPORT AND THE INFLUENCE TO STUDENT DISCIPLINE \\ Oleh: \\ Santi Maria Permatasari ${ }^{1}$ \\ Farida Kurniawati ${ }^{2}$
}

\begin{abstract}
Submitted:

02 Januari 2020

Revision:

19 Mei 2020

Accepted:

23 Juni 2020

Picky eating behavior in children cause distress for parents because the impacts on children's health and family eating activities. Picky eating can be influenced by feeding practices. Feeding practices consist of restriction / control feeding, pressure to eat, and child monitoring. The purpose of this scientific literacy study is to collect a general overview on the feeding practices that applied by parents of picky eating children. The research method is a literature review using studies obtained from several databases. There are 7 quantitative studies selected with participants parents whose children aged 1-12 years, and using instruments to measure picky eating and feeding practices. The result shows that parents apply pressure to eat and restriction / control feeding in feeding practices in children who exhibit picky eating behavior. This research is expected to increase parental awareness about appropriate feeding practices implemented in order to reduce the risk of children experiencing picky eating.
\end{abstract}

Keywords: Children; Feeding Practices; Picky Eating

\begin{abstract}
ABSTRAK
Perilaku picky eating pada anak meresahkan orang tua karena dapat berdampak pada kesehatan anak dan proses kegiatan makan keluarga. Picky eating dapat dipengaruhi dari faktor lingkungan, salah satunya feeding practices. Feeding practices terdiri atas restriction/control feeding, pressure to eat, dan monitoring child. Tujuan kajian literasi ilmiah ini adalah mengumpulkan gambaran umum studi ilmiah tentang feeding practices yang diterapkan orang tua pada anak picky eating. Metode penelitian ini adalah kajian literatur dengan menggunakan studi yang diperoleh dari beberapa database. Terdapat 7 studi kuantitatif yang terpilih dengan partisipan dalam penelitian orang tua yang memiliki anak berusia 1-12 tahun, serta menggunakan instrument untuk mengukur perilaku picky eating pada anak dan feeding practice yang diterapkan orang tua. Hasil menunjukkan orang tua menerapkan pressure to eat dan restriction/control feeding dalam feeding practices pada anak yang menunjukkan perilaku picky eating. Penelitian ini diharapkan dapat meningkatkan kesadaran orang tua mengenai feeding practice yang tepat diterapkan agar mengurangi risiko anak mengalami picky eating.
\end{abstract}

Kata kunci: Anak; Feeding Practices; Picky Eating

\section{PENDAHULUAN}

Orang tua pada umumnya menginginkan asupan bergizi untuk anaknya, namun sering kali orang tua menemui kesulitan dalam perilaku makan anak. Banyak orang tua yang kesulitan untuk mengajarkan anak dalam pola makan sehat karena perilaku susah makan,

\footnotetext{
${ }^{1}$ Santi Maria Permatasari, Universitas Indonesia, eleonorasanti95@gmail.com

2 Farida Kurniawati, Universitas Indonesia, faridakurniawati@gmail.com
} 
seperti picky eating dan neophobia yang sering ditemui pada anak (Cano dkk., 2015). Berdasarkan reviu literatur oleh Taylor dkk. (2015), picky eating sering dijumpai pada anakanak dan dimulai saat anak sudah mulai dapat mengunyah makanan. Anak mulai dapat diperkenalkan makanan solid disarankan sejak berusia 6 bulan. Pada awalnya, anak diberikan makanan yang berbentuk bubur menyerupai cairan hingga bertahap makanan yang mulai bertekstur, hingga makanan seperti orang dewasa (Papalia \& Martorell, 2015). Reviu literatur yang dilakukan oleh Taylor dkk. (2015) dilakukan pada sejumlah negara seperti Cina, Belanda, Selandia Baru, Australia, Amerika Serikat, Jepang, Norwegia, Itali, Turki, Singapura, Denmark, Jerman, Kanada, dan Inggris.

Picky eating atau disebut juga sebagai fussy eating, faddy eating, dan choosy eating terkadang dapat muncul pada spektrum dari gangguan makan. Picky eating dianggap sebagai tahap awal munculnya gangguan makan yang serius jika tidak adanya penanganan atau prevensi awal. Saat ini definisi picky eating masih menjadi perdebatan. Berdasarkan kajian dari beberapa ahli, picky eating ialah terbatasnya jenis makanan yang dikonsumsi karena adanya penolakan terhadap makanan yang familiar maupun tidak familiar, serta dapat juga mencakup penolakan terhadap makanan dengan tekstur tertentu (Dovey dkk., 2008). Dengan demikian, definisi picky eating ialah terbatasnya jumlah makanan yang dimakan, ketidakinginan dalam mencoba makanan baru, terbatasnya jumlah sayuran dan grup makanan lainnya yang dimakan, memiliki preferensi makanan yang kuat (suka/tidak suka), serta mencakup perlunya makanan khusus yang disiapkan (Horst dkk., 2014).

Perilaku picky eating tidak termasuk di dalam kategori gangguan mental yang terdaftar pada DSM-V, namun terdapat korelasi antara perilaku picky eating yang ditunjukkan anak dengan gangguan mental. Anak yang memiliki perilaku susah makan atau tidak tertarik dengan makanan dapat menjadi permulaan dalam gangguan psikologis ketika remaja (Mash \& Wolfe, 2016). Ketika perilaku picky eating ini tidak diberikan perhatian lebih, maka dapat menjadi factor resiko anak mengalami gangguan makan, seperti Pica dan Avoidant/Restrictive Food Intake Disorder (ARFID) karena anak dapat mengalami penurunan berat badan secara tiba-tiba dan terganggunya perkembangan emosi serta sosial (Mash \& Wolfe, 2013).

Perilaku picky eating memiliki dampak buruk terhadap kesehatan anak, seperti meningkatkan risiko berat badan yang kurang (Ekstein dkk., 2010), perkembangan yang buruk (Wright dkk., 2007), dan risiko konstipasi karena kurangnya asupan makanan sehat (Tharner dkk., 2015). Dampak buruk terhadap kesehatan semakin bertambah karena anak picky eating juga sering kali menunjukkan ketidaksukaan pada makanan sehat seperti daging dan ikan (Tharner dkk., 2014), serta buah dan sayuran yang dapat berpotensi terhadap kurangnya nutrisi pada anak (Horodynski dkk., 2010). Mengingat dampaknya yang besar terhadap kesehatan anak, maka penanganan terhadap gangguan ini perlu menjadi perhatian.

Perilaku picky eating tidak hanya berdampak buruk bagi kesehatan anak, namun juga berdampak pada proses kegiatan makan keluarga. Beberapa orang tua menyatakan bahwa anak mereka yang memiliki perilaku picky eating dianggap mengganggu kegiatan makan keluarga. Picky eating menyebabkan orang tua menjadi stres dan frustrasi ketika melakukan kegiatan makan bersama keluarga. Hal tersebut terjadi karena orang tua merasa picky eating dapat menyebabkan makanan terbuang sia-sia karena anak tersebut tidak mau makan. Selain itu, beberapa orang tua mengaku frustrasi dan kewalahan ketika harus menyiapkan menu makanan khusus untuk anak picky eating yang berbeda dari anggota keluarga yang lain (Trofholz dkk., 2010). Orang tua juga menunjukkan kekhawatiran karena merasa standar makanan yang dimakan tidak sesuai dengan standar kesehatan karena standar makanan yang diberikan disesuaikan dengan selera anak (Trofholz dkk., 2017).

Picky eating dapat dipengaruhi dari faktor lingkungan, salah satunya feeding practices yang diterapkan oleh pengasuh selama anak makan baik saat anak masih meminum ASI, 
mulai makan makanan yang cair, bertekstur, hingga anak makan makanan layaknya orang dewasa (Cooke \& Webber, 2015). Hal tersebut terlihat dari hasil observasi oleh Luchini dkk. (2017) yang membedakan perilaku makan anak di tempat penitipan dan di rumah. Hasil observasi menunjukkan lebih banyak anak yang picky eating di rumah daripada di tempat penitipan anak. Hal tersebut terjadi karena adanya perbedaan kondisi dalam memberikan makanan untuk anak, seperti banyaknya makanan yang diberikan dan pendekatan yang dilakukan agar anak mau mencoba makanan, atau yang disebut dengan feeding practices. Perbedaan feeding practices dapat menjadi faktor penyebab dari munculnya perilaku picky eating pada anak.

Feeding practices ialah perilaku spesifik yang dilakukan orang tua dalam menentukan apa, kapan, atau seberapa banyak makanan anak (Blisset, 2011). Feeding practices merupakan upaya yang dilakukan orang tua yang dapat mempengaruhi perilaku makan anak, baik meningkatkan maupun menurunkan asupan makanan pada anak. Feeding practices terdiri atas restriction/control feeding, pressure to eat, dan monitoring child intake (Shloim dkk., 2015). Orang tua yang menggunakan restriction/control feeding akan membatasi secara ketat akses anak pada makanan atau kesempatan anak untuk mengkonsumsi makanan.

Hal tersebut dilakukan agar dapat mengontrol asupan makanan yang tidak sehat pada anak, seperti makanan yang terlalu manis atau makanan cepat saji. Sedangkan pressure to eat ialah pendekatan orang tua dengan bersikeras, menuntut, dan berupaya agar anak makan lebih banyak makanan. Upaya yang dilakukan ialah menuntut anak untuk menghabiskan makanan yang sudah disediakan di piring dan menuntut anak untuk makan walaupun anak tersebut sedang tidak lapar. Terakhir, monitoring child intake ialah pendekatan orang tua dalam perilaku makan anak dengan memperhatikan mengenai jenis makanan dan seberapa banyak makanan yang dimakan anak. Hal tersebut bertujuan agar orang tua dapat memastikan anak memakan makanan yang sehat dalam jumlah yang cukup dan menghindari agar anak tidak berlebihan dalam memakan makanan tidak sehat (Vaughn dkk., 2016).

Berdasarkan pemaparan tersebut, setiap pendekatan dari feeding practices memiliki cara berbeda-beda yang dilakukan orang tua dalam kegiatan memberi makan pada anak. Orang tua memiliki kebebasan memilih pendekatan feeding practices untuk anaknya di rumah. Ketika orang tua memiliki anak yang dideskripsikan sebagai picky eating, orang tua akan berusaha mencari dan menerapkan berbagai pendekatan feeding practices agar anak dapat makan makanan yang sehat. Akan tetapi, terkadang orang tua dapat menggunakan penerapan feeding practices yang kurang tepat yang dapat mempengaruhi perkembangan dalam pola makan sehat (Galloway dkk., 2005). Dengan demikian, tujuan kajian literasi ilmiah ini adalah mengumpulkan gambaran umum studi ilmiah tentang feeding practices yang diterapkan orang tua pada anak picky eating.

\section{METODE PENELITIAN}

\section{Sumber Data dan Strategi Pencarian}

Pada studi ini, sumber data yang didapatkan melalui alat pencarian riset dari Perpustakaan Universitas Indonesia. Database seleksi literatur pada penelitian ini yaitu Proquest dan ScienceDirect. Pencarian sumber data menggunakan batasan periode publikasi sejak Januari 2009 sampai Oktober 2019. Penelusuran dilakukan dari tanggal 23 Oktober 2019 hingga tanggal 26 Oktober 2019. Proses seleksi studi yang dieleminasi dan studi yang diikutsertakan pada analisis lanjutan terdiri atas screening, pembacaan, dan identifikasi judul atau abstrak studi-studi dari kedua database. Peneliti menyaring data pencarian hanya untuk artikel penelitian ilmiah yang sudah melalui proses peer review.

Kata kunci pencarian pada database Proquest yakni: (a) ('picky eating' AND 'feeding practice' AND 'early childhood') dan (b) ('choosy eating' AND 'feeding practice' AND 'early childhood'). Dari proses pertama (a), peneliti menemukan 299 studi ilmiah sebelum 
seleksi lanjutan yang berkaitan dengan kata kunci. Dari proses kedua (b), peneliti menemukan 22 studi terkait kata kunci. Berdasarkan pencarian database pertama, jumlah studi terseleksi yakni 4 penelitian yang merupakan penelitian kuantitatif.

Selanjutnya, pencarian melalui database ScienceDirect adalah dengan menggunakan kata kunci sebagai berikut (a) ('picky eating' AND 'feeding practice' AND 'early childhood') dan (b) ('choosy eating' AND 'restriction/control feeding' AND 'pressure to eat' AND 'monitoring child intake' AND 'early childhood'). Dari proses pertama (a), peneliti menemukan 263 studi ilmiah sebelum seleksi lanjutan yang berkaitan dengan kata kunci. Dari proses kedua (b), peneliti menemukan 133 studi terkait kata kunci. Pada database kedua, studi terpilih hanya berjumlah 3 studi. Seleksi yang dilakukan berdasarkan pada eliminasi studi-studi yang berada pada luar konteks pencarian, seperti kriteria partisipan yang tidak sesuai dengan konteks anak dan studi mengenai faktor yang melatarbelakangi feeding practices.

\section{Pemilihan Studi}

Pada pencarian studi, peneliti menemukan studi yang mempunyai judul yang sama dengan menggunakan kata kunci yang berbeda. Setelah itu, studi dengan judul yang sama diputuskan untuk diakumulasi dengan proses yang pertama kali, seperti studi oleh Sandvik dkk. (2018) untuk pencegahan diplikasi. Proses pemilihan data terdiri atas: (1) identifikasi judul dan abstrak; (2) screening artikel penelitian pada tujuan penelitian dan hasil; dan (3) keputusan studi terpilih atau tereleminasi.

Dari total 321 studi dari pencarian database Proquest, 27 studi dipertimbangkan sampai memasuki tahap penilaian, dan hanya 4 studi yang diputuskan untuk digunakan. Beberapa alasan artikel dieleminasi adalah: (1) partisipan penelitian tidak berada dalam rentang usia anak-anak; (2) pengujian pada variabel lain yang tidak berkaitan. Hasil dari proses pencarian database ini diperlihatkan dalam diagram pada Gambar 1.

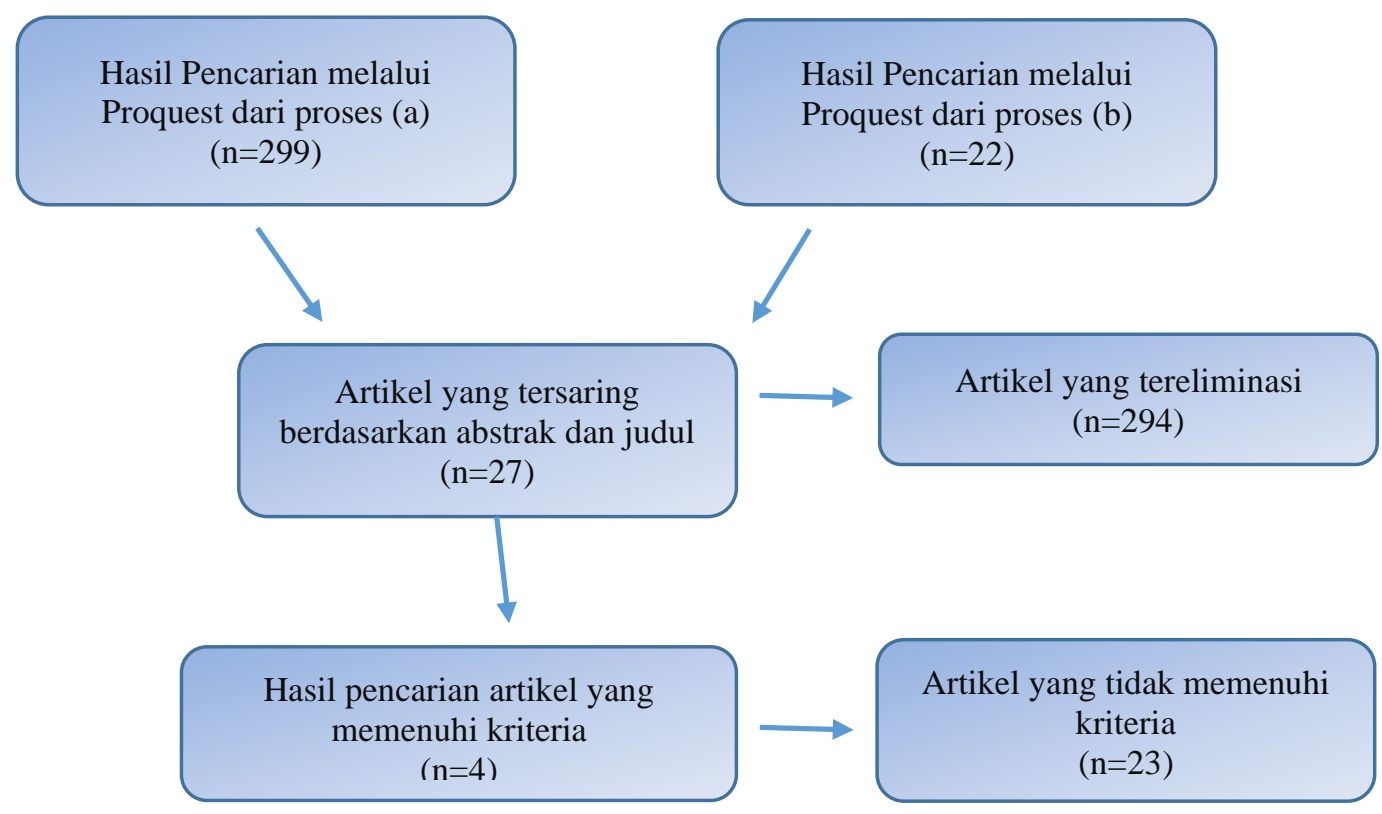

Gambar 1. Diagram pencarian studi ilmiah pada database Proquest

Pada database ScienceDirect, terdapat 25 studi yang dipertimbangkan, dan terseleksi hanya 3 studi. Beberapa alasan artikel dieleminasi adalah: (1) partisipan penelitian tidak berada dalam rentang usia anak-anak; (2) pengujian pada variabel lain yang tidak berkaitan. Hasil dari proses pencarian database ini diperlihatkan dalam diagram pada Gambar 2. 


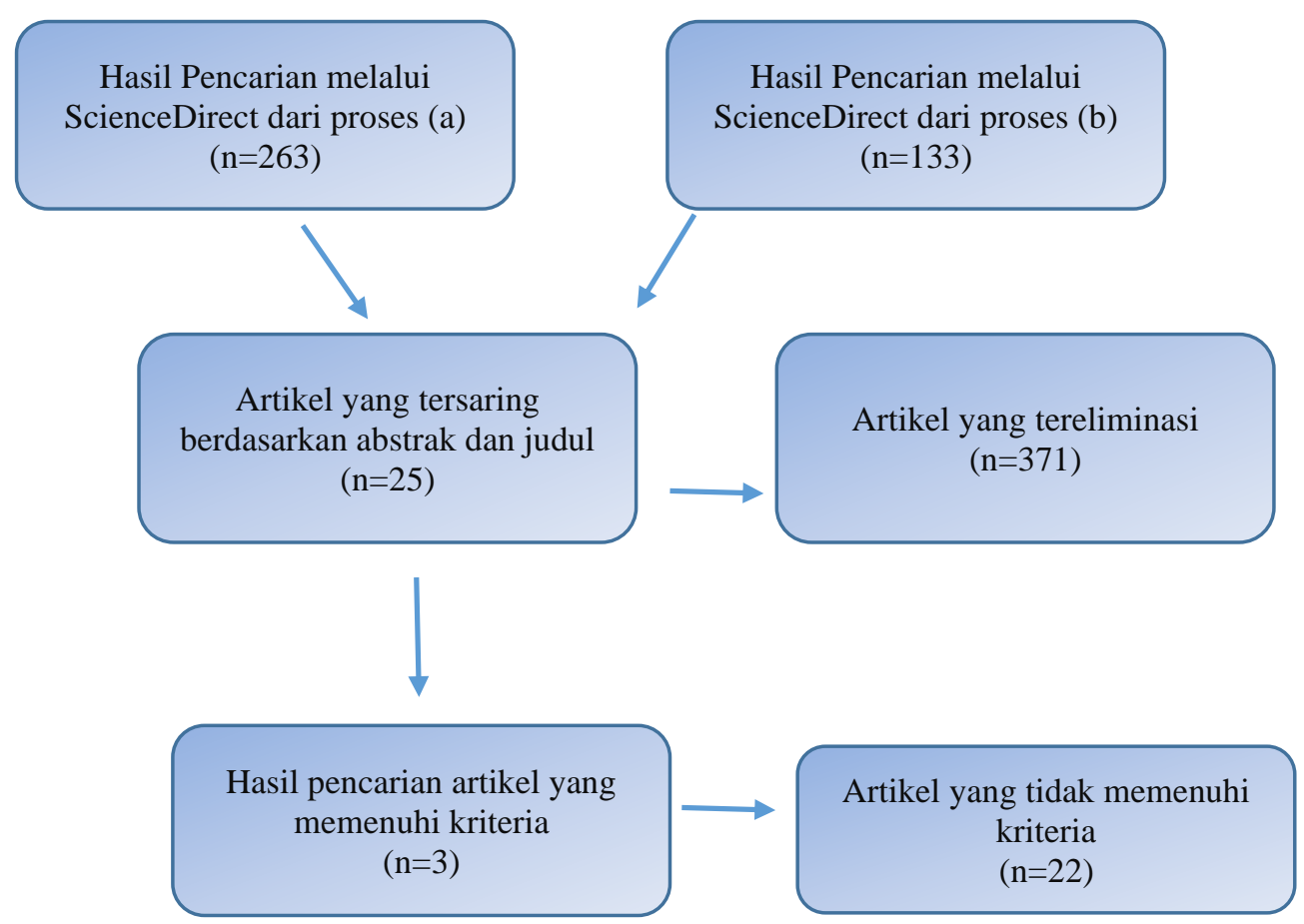

Gambar 2. Diagram pencarian studi ilmiah pada database ScienceDirect

Dari total 717studi dari kedua database, tereleminasi 710 studi dan terseleksi 7 artikel jurnal yang sesuai dengan kriteria untuk dikaji lebih lanjut mengenai gambaran feeding practices yang diterapkan orang tua pada anak picky eating.

\section{HASIL DAN PEMBAHASAN}

Studi yang dikaji berjumlah 7 dan merupakan studi kuantitatif. Hasil dari studi ilmiah yang dikaji dari ketujuh studi disajikan dalam Tabel 1.

Tabel 1.

Gambaran Umum Studi Terpilih

Gambaran Feeding Practice yang diterapkan orang tua pada anak picky eating

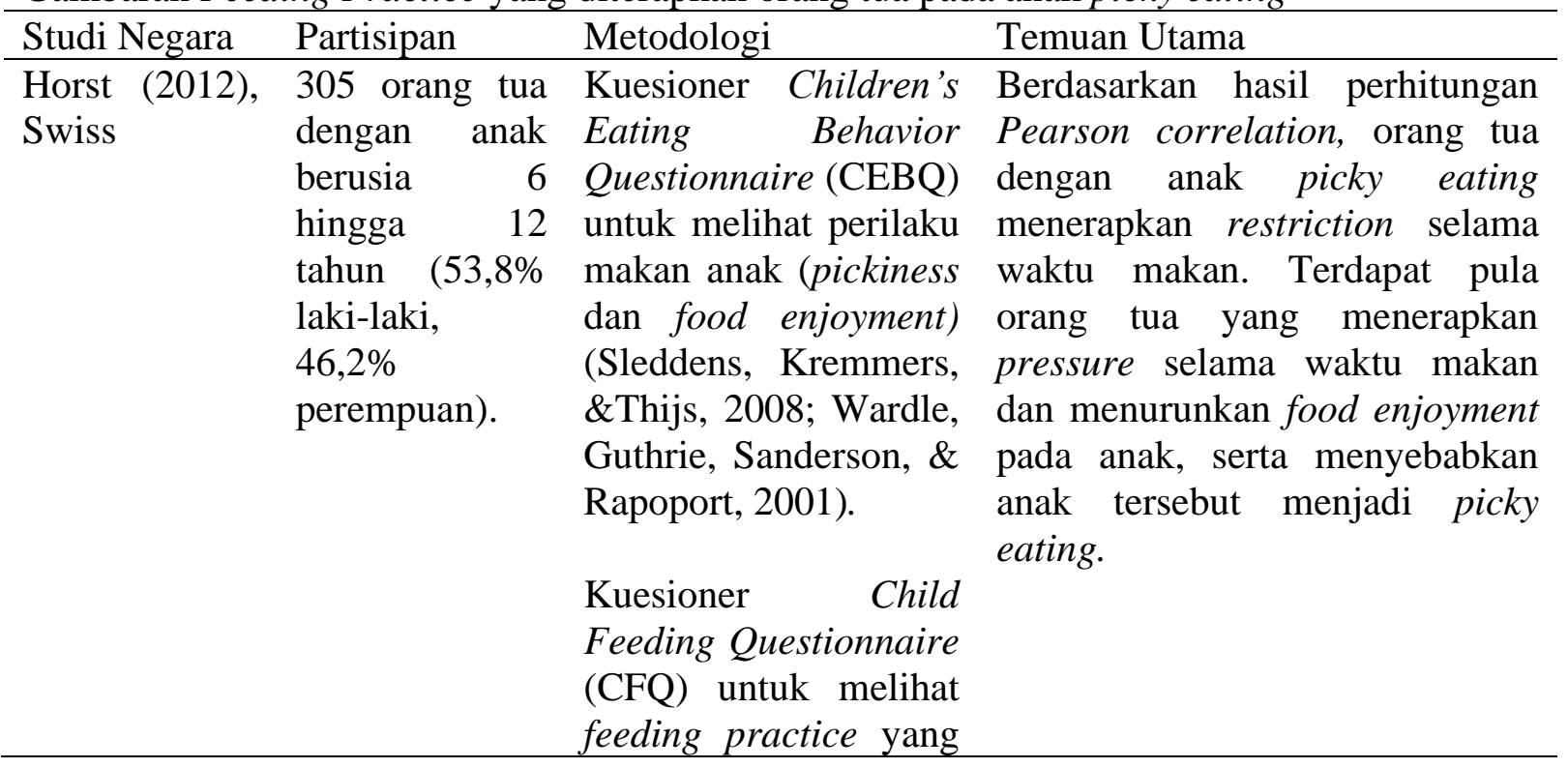




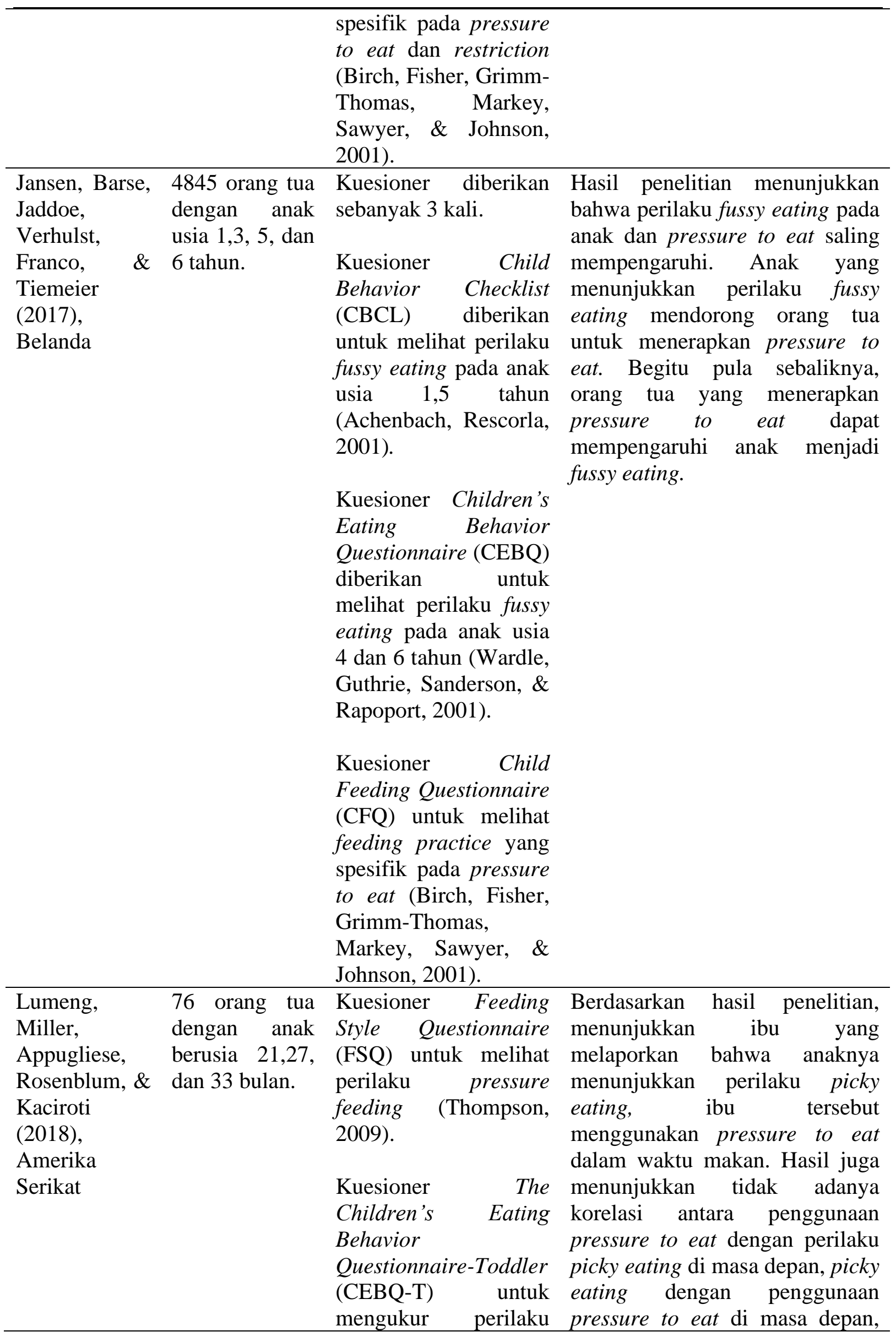


picky eating pada anak (Carnell \& Wardle, 2007).

Kuesioner The Brief Autism Mealtime

Behavior Inventory

(BAMBI) untuk

mengukur perilaku picky eating pada anak (Lukens \& Linscheid, 2008).

Berat badan anak diukur oleh peneliti dan dibandingkan dengan z-socre dari United States Centers for Disease Control Growth Charts.

\begin{tabular}{llrl}
\hline Haszard, & & 193 keluarga & Anak diukur tinggi dan \\
Skidmore, & & dengan anak & berat badannya (BMI) \\
Williams, \& & berusia & 4 & lalu dibandingkan \\
Taylor, & & hingga 8 tahun & dengan the center for \\
(2014), & dan & berat & disease control and \\
Selandia & badan yang & prevention's growth \\
Baru & overweight. & charts & menentukan kategori \\
& & & berat badan anak.
\end{tabular}

Kuesioner

Comprehensive

Feeding Practices

Questionnaire (CFPQ) untuk melihat feeding practice yang diterapkan orang tua (Hazard, Williams, Dawson, Skidmore, \& Taylor, 2013).

Kuesioner

Lifestyle

Behavior

Checklist

(LBC) untuk melihat perilaku fussy eating pada anak (West \& Sanders, 2009).

\begin{tabular}{llrlrl}
\hline Harris, Fildes, & Ibu dengan & Kuesioner Child & Hasil yang terlihat adalah ibu \\
Mallan, & anak kembar. & Feeding Questionnaire menggunakan pressure to eat \\
Llewellyn, & Jumlah anak & (CFQ) untuk melihat sebagai feeding practice pada \\
\hline
\end{tabular}

Berdasarkan hasil telah terlihat bahwa orang tua menggunakan pressure to eat sebagai feeding practice untuk anak yang dilaporkan menunjukkan perilaku fussy eating. Hal ini dapat terjadi karena orang tua memungkinkan untuk memaksa anak makan jika anak menunjukkan penolakan selama tua juga menggunakan restriction feeding pada anak yang menunjukkan perilaku fussy eating. Hal ini mungkin terjadi karena anak merasa bingung mengenai apa dan kapan ia harus makan. waktu makan. Selain itu, orang umlah anak 


\begin{tabular}{|c|c|c|c|}
\hline \multirow[t]{2}{*}{$\begin{array}{l}\text { (2016), } \\
\text { Britania Raya }\end{array}$} & \multirow[t]{2}{*}{$\begin{array}{l}\text { yang diteliti } \\
\text { sebanyak } 1013 \\
\text { anak usia dini. }\end{array}$} & $\begin{array}{l}\text { feeding practice yang } \\
\text { diterapkan orang tua } \\
\text { (Sweetman, Mcgowan, } \\
\text { Croker, \& Cooke, } \\
\text { 2011). }\end{array}$ & $\begin{array}{l}\text { salah satu anak kembar yang } \\
\text { lebih menunjukkan perilaku } \\
\text { fussy eating. Hal ini mungkin } \\
\text { terjadi karena feeding practice } \\
\text { yang diterapkan ibu disesuaikan } \\
\text { dengan bagaimana perilaku }\end{array}$ \\
\hline & & $\begin{array}{l}\text { Kuesioner Children's } \\
\text { Eating Behavior } \\
\text { Questionnaire (CEBQ) } \\
\text { untuk mengukur fussy } \\
\text { eating pada anak } \\
\text { (Wardle, Guthire, } \\
\text { Sanderson, \& } \\
\text { Rapoport, 2001). }\end{array}$ & $\begin{array}{l}\text { makan anak. Sedangkan, ibu } \\
\text { menggunakan restriction sebagai } \\
\text { feeding practice pada anak yang } \\
\text { tidak fussy eating. Hal ini terjadi } \\
\text { karena asupan makanan yang } \\
\text { diberikan kepada anak dan nafsu } \\
\text { makan anak diatur ibu. }\end{array}$ \\
\hline \multirow[t]{3}{*}{$\begin{array}{l}\text { Jordan, } \\
\text { Appugliese, } \\
\text { Miller, } \\
\text { Lumeng, } \\
\text { Rosenblum, } \\
\text { Pesch, (2020), } \\
\text { Amerika } \\
\text { Serikat }\end{array}$} & \multirow[t]{3}{*}{$\begin{array}{l}199 \text { ibu dengan } \\
\text { anak berusia } \\
\text { rata-rata } 6 \\
\text { tahun dengan } \\
\text { status sosial } \\
\text { ekonomi } \\
\text { rendah. }\end{array}$} & 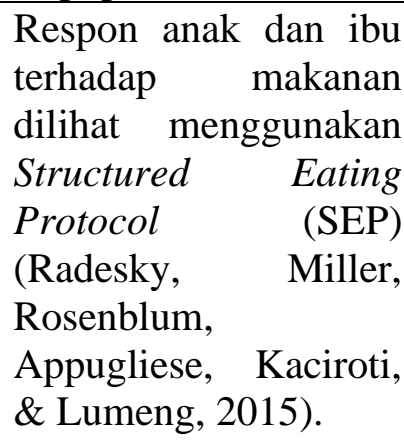 & $\begin{array}{l}\text { Hasil menunjukkan bahwa ibu } \\
\text { menggunakan pressure to eat } \\
\text { pada anak yang picky eating } \\
\text { daripada anak yang tidak picky } \\
\text { eating. Kemudian, ibu akan lebih } \\
\text { menggunakan pressure to eat } \\
\text { pada anak yang tidak mau makan } \\
\text { sayur dibandingkan anak yang } \\
\text { mau makan sayur. }\end{array}$ \\
\hline & & $\begin{array}{lr}\text { Kuesioner } & \text { Caregiver } \\
\text { Feeding } & \text { Style } \\
\text { Questionnaire (CFSQ) } & \text { untuk melihat } \\
\text { feeding } \\
\text { practices r yang } \\
\text { diterapkan } r \text { ibu } \\
\text { (Hughes, Power, } \\
\text { Orlet-Fisher, Mueller, } \\
\text { \& Nicklas, 2005). }\end{array}$ & \\
\hline & & $\begin{array}{l}\text { Kuesioner Preschooler } \\
\text { Feeding Questionnaire } \\
\text { (PFQ) untuk melihat } \\
\text { feeding believes ibu } \\
\text { terhadap anak (Pesch, } \\
\text { Miller, Appugliese, } \\
\text { Rosenblum, Lumeng, } \\
\text { 2016). }\end{array}$ & \\
\hline $\begin{array}{l}\text { Sandvik, Ek, } \\
\text { Somaraki, } \\
\text { Hammar, Eli, } \\
\text { Nowicka, } \\
\text { (2018), } \\
\text { Swedia }\end{array}$ & $\begin{array}{lr}876 \text { ibu dengan } \\
\text { anak berusia } 4 \\
\text { tahun. Jumlah } \\
\text { anak yang } \\
\text { diteliti } \\
\text { sebanyak } & 1272 \\
\text { anak. }\end{array}$ & $\begin{array}{lr}\text { Kuesioner } & \text { Children's } \\
\text { Eating } & \text { Behavior } \\
\text { Questionnaire (CEBQ) } & \\
\text { untuk mengukur fussy } \\
\text { eating pada anak (Ek, } \\
\text { Sorjonen, } \\
\text { Lindberg, Nli, } \\
\text { Marcus, Nyman, }\end{array}$ & $\begin{array}{l}\text { Hasil menunjukkan bahwa pada } \\
\text { anak picky eating yang memiliki } \\
\text { berat badan kurang dan normal, } \\
\text { ibu menerapkan pressure to eat } \\
\text { dalam feeding practice karena } \\
\text { orang tua merespon perilaku } \\
\text { anak seperti berteriak dan } \\
\text { tantrum ketika diberi makanan. }\end{array}$ \\
\hline
\end{tabular}




\begin{tabular}{|c|c|}
\hline 2016). & Akan \\
\hline Kuesioner & $\begin{array}{l}\text { menerapkan pressure to eat pada } \\
\text { anak picky eating vang memiliki }\end{array}$ \\
\hline Feeding Questionnaire & berat badan overweight. Hal ini \\
\hline (CFQ) untuk melihat & terjadi karena ketika \\
\hline feeding practice yang & menerapkan pressure to eat \\
\hline spesifik pada pressure & kemampuan \\
\hline to eat (Nowicka, & meregulasi makanan yang masuk \\
\hline Sorjonen, Pietrobelli, & menurun. \\
\hline $\begin{array}{l}\text { Flodmark, \& Faith, } \\
\text { 2014). }\end{array}$ & \\
\hline
\end{tabular}

Berdasarkan hasil dari studi ilmiah yang dipilih, telah terlihat bahwa feeding practice yang diterapkan pengasuh pada anak picky eating ialah pressure to eat. Dari 7 studi ilmiah yang dikaji, ketujuh studi menunjukkan bahwa pengasuh menggunakan pressure to eat sebagai feeding practice pada anak yang berperilaku picky eating. Akan tetapi, terdapat 1 studi yang menunjukkan pressure to eat tidak diterapkan untuk anak dengan picky eating karena adanya karakteristik tertentu pada anak tersebut. Selain itu, terdapat pula dua studi yang menunjukkan bahwa orang tua menggunakan restriction sebagai feeding practice pada anak yang picky eating. Namun, terdapat satu studi yang menunjukkan bahwa restriction tidak digunakan pada anak yang picky eating. Hal tersebut akan dikaji lebih lanjut dibagian diskusi.

Ketujuh studi ilmiah yang dikaji telah terlihat bahwa orang tua menerapkan pressure to eat sebagai feeding practice untuk anak yang dianggap berperilaku picky eating selama waktu makan. Alasan orang tua menerapkan pressure to eat pada anak yang dianggap picky eating bermacam-macam. Berdasarkan hasil kajian dari penelitian Harris dkk. (2016) ditemukan bahwa sudah menjadi intuisi orang tua untuk mengontrol makanan yang dimakan anak agar berat badan anak normal. Hal ini dilakukan orang tua sebagai bentuk sikap orang tua terhadap perilaku makan anak yang menunjukkan picky eating agar anak mendapatkan nutrisi yang cukup (Goh \& Jacob, 2012). Selain itu, orang tua cenderung untuk menerapkan pressure to eat ketika waktu makan karena mereka memiliki perasaan khawatir melihat anak menolak makan atau makan dalam jumlah yang sedikit. Orang tua akan mencoba untuk memberikan makan dalam jumlah yang banyak dan berbeda-beda karena mereka tidak ingin anaknya mengalami kekurangan nutrisi dan berat badan yang kurang (Janse dkk., 2017). Hal ini sesuai dengan hasil penelitian lain yang menyatakan orang tua menerapkan pressure to eat sebagai respon intervensi terhadap anak yang picky eating agar perkembangan anak tidak terganggu (Lumeng dkk., 2018) dan juga penelitian lain yang menyatakan ibu akan menerapkan pressure to eat pada anaknya yang picky eating sebagai bentuk respon terhadap takutnya ibu jika anak mengalami berat badan yang terlalu rendah (Gregory dkk., 2010).

Di lain pihak, pressure to eat juga makin mendorong anak menampilkan perilaku picky eating. Pressure to eat memicu perasaan negatif anak pada makanan yang disajikan, sehingga membuat anak makin berperilaku picky eating (Jansen dkk., 2017). Berdasarkan dua studi ilmiah yang dikaji menunjukkan tidak hanya pressure to eat saja yang diterapkan pada anak picky eating, namun restriction juga merupakan feeding practice yang diterapkan orang tua dengan anak picky eating. Pressure to eat dan restriction dianggap sebagai feeding practice yang sangat mengatur seberapa banyak makanan yang harus dimakan anak dan anak harus mengikuti peraturan tersebut. Feeding practices yang terlalu mengontrol anak dapat membuat atmosfer negatif selama kegiatan makan anak, serta membuat anak tidak menikmati makanannya yang berdampak pada munculnya perilaku picky eating. 
Penggunaan kedua feeding practices tersebut dapat mengganggu kemampuan regulasi anak dalam kegiatan makan dan menimbulkan hubungan yang tidak baik dengan makanan (Horst, 2012). Hal ini selaras dengan penelitian sebelumnya bahwa orang tua yang menerapkan kontrol pada kegiatan anak dapat membuat anak picky eating terutama pada makanan yang baru ditemui (Fries dkk., 2017). Dampak negatif dari kedua feeding practice tersebut ternyata tidak hanya membuat anak menjadi picky eating saja, namun juga berdampak pada perilaku makan anak di kemudian hari ketika sudah di usia dewasa. Hal ini terjadi karena perkembangan individu terutama pada intuisi dan feeding practice yang adaptif tidak berkembang (Ellis dkk., 2016).

Berat badan anak juga memiliki kaitan dengan perilaku picky eating pada anak dan penerapan feeding practice orang tua. Berdasarkan studi ilmiah yang dikaji dari penelitian oleh Haszard dkk. (2014), telah terlihat bahwa anak yang memiliki berat badan berlebih juga menunjukkan picky eating ketika orang tua menerapkan pressure to eat dan restriction sebagai feeding practice. Hal ini dapat terjadi karena orang tua terlalu mengontrol makanan yang diberikan kepada anak dan menggunakan makanan yang diinginkan anak sebagai reward ketika memakan makanan utama yang tidak disukai anak. Makanan yang dijadikan reward biasanya makanan yang mengandung banyak lemak dan gula, seperti sereal, roti, pasta, kentang goreng, coklat susu, es krim, dan lain-lain (Hendy, dkk., 2013). Selain itu, anak juga menjadi overweight karena anak menjadi terbiasa untuk makan walaupun tidak merasa lapar secara biologis (Galindo dkk., 2018). Hal tersebut tampak beberapa tahun kemudian setelah ibu menerapkan pressure to eat pada anak secara terus-menerus.

Hasil kajian studi ilmiah tersebut berbeda dengan penelitian oleh Sandvik dkk. (2018), yang menyatakan bahwa anak dengan berat badan kurang dan normal yang picky eating membuat orang tuanya menerapkan pressure to eat selama waktu makan. Akan tetapi, orang tua tidak menerapkan pressure to eat pada anak dengan berat badan berlebih. Hal tersebut dapat terjadi karena pressure to eat membuat anak tidak mampu meregulasi makanan yang dimakan dan sering kali makan makanan yang tidak sehat dalam jumlah banyak. Dengan demikian, orang tua dengan anak berat badan berlebih menghindari perilaku makan makanan tidak sehat terlalu banyak, sehingga mereka tidak menerapkan feeding practice tersebut selama waktu makan. Dapat terlihat, pernerapan pressure to eat dapat memperngaruhi kesehatan anak secara umum dan dapat pula menyebabkan dampak negatif terhadap perkembangan anak usia dini.

Hal ini terjadi karena pressure to eat membuat anak tidak memiliki kontrol diri dalam makan dan terdapat pemaksaan untuk makan tanpa memperhatikan kebutuhan biologis anak (Dranesia dk., 2019). Hal ini selaras dengan penelitian yang menyatakan bahwa anak yang tidak memiliki kontrol akan pola makannya, maka anak akan cenderung menunjukkan sikap picky eating. Hal ini terjadi karena pola makan anak diatur dari luar diri anak dan bukan dari dalam anak, yaitu inisiatif anak untuk makan sebagai respon dari rasa lapar yang dirasakannya (Rowell \& Mcglothlin, 2015).

\section{KESIMPULAN}

Berdasarkan paparan yang telah dibahas sebelumnya, dapat disimpulkan bahwa feeding practice yang diterapkan oleh orang tua dengan anak picky eating ialah pressure to eat dan restriction. Kedua feeding practice tersebut memiliki karakteristik yang serupa, yaitu adanya kontrol berlebih oleh orang tua selama waktu makan anak. Pada kedua feeding practice, anak diharuskan mengikuti aturan makan yang diberikan orang tua, sehingga anak tidak memiliki kontrol pada waktu makan. Orang tua menerapkan feeding practice tersebut juga dengan bermacam-macam alasan, terutama karena adanya ketakutan anak memiliki berat badan yang kurang dan kekurangan nutrisi. 
Ketujuh penelitian yang relevan dengan tujuan literature review ini belum bisa digeneralisasi karena beberapa hal. Pertama, jumlah artikel yang digunakan pada review ini terbatas sehingga kesimpulan yang diambil masih harus dibuktikan kembali. Berdasarkan ketujuh studi ilmiah yang dikaji, tidak ada yang menampilkan hasil mengenai feeding practices selain pressure to eat dan restriction. Kedua, instrumen yang digunakan oleh ketujuh penelitian adalah kuesioner sehingga hasil yang diperoleh dari partisipan memungkinkan adanya kecenderungan social desirability yang tinggi. Pada kajian literature review selanjutnya perlu mengkaji feeding practice lainnya agar mendapatkan gambaran menyeluruh mengenai feeding practice yang digunakan dan tidak digunakan oleh orang tua dengan anak picky eating. Dengan demikian, dapat memberikan implikasi feeding practice yang baik digunakan agar anak tidak menunjukkan perilaku picky eating.

\section{DAFTAR PUSTAKA}

Blisset, J. (2011). Relationships between parenting style, feeding style, and feeding practices and fruit and vegetable consumption in early childhood. Appetite, 57 (3), 826-831. https://doi.org/10.1016/j.appet.2011.05.318

Cano, S.C., Tiemeier, H., Hoeken, D.V., Tharner, A., Jaddoe, V.W.V., Hofman, A., Verhulst, F.C., \& Hoek, H.W. (2015). Trajectories of picky eating during childhood: A general population study. International Journal of Eating Disorders, 48(6), 570-579. https://doi.org/10.1002/eat.22384

Cooke, L. \& Webber, L. (2015). Stress free feeding: How to develop healthy eating habits in your child. Robinson.

Dovey, T.M., Staples, P.A., Gibson, E.L., Halford, J.C. (2008). Food neophobia and picky/fussy eating in children: A review. Appetite, 50 (2), 181-193. https://doi.org/10.1016/j.appet.2007.09.009

Dranesia, A., Wanda, D., \& Hayati, H. (2019). Pressure to eat is the most determinant factor of stunting in children under 5 years of age in Kerinci region, Indonesia. Enfermeria Clinica, 29 (2), 81-86. https://doi.org/10.1016/j.enfcli.2019.04.013

Ekstein, S., Laniado, D., \& Glick, B. (2010). Does picky eating affect weight for length measurements in young children? Clinical Pediatrics, 49, 217-220. https://doi.org/10.1177/0009922809337331

Ellis, J.M., Galloway, A.T., Webb, R.M., Martz, D.M., \& Farrow, C.V. (2016). Recollections of pressure to eat during childhood, but not picky eating, predict young adult eating behavior. Appetite, 97, 58-63. https://doi.org/10.1016/j.appet.2015.11.020

Fries, L.R., Martin, N., \& Horst, K. (2017). Parent-child mealtime interactions associated with toddler's refusals of novel and familiar foods. Psychology and Behavior, 176, 93-100. https://doi.org/10.1016/j.physbeh.2017.03.001

Galindo, L., Power, T.G., Beck, A.D., Fisher, J.O., O’Connor, T.M., \& Hughes, S.O. (2018). Predicting preschool children's eating in the absence of hunger from maternal pressure to eat: A longitudinal study of low-income, Latina mothers. Appetite, 120, 281-286. https://doi.org/10.1016/j.appet.2017.09.007

Galloway, A.T., Fiorito, L., Lee, Y., \& Birch, L.L. (2005). Parental pressure, dietary patterns, and weight status among girls who are "picky eaters". Journal of the American Dietetic Association, 105(4), 541-548. https://doi.org/10.1016/j.jada.2005.01.029

Goh, D.Y.T. \& Jacob, A. (2012). Perception of picky eating among children in Singapore and its impact on caregivers: A questionnaire survey. Asia Pasific Family Medicine, 11 (5). https://doi.org/10.1186/1447-056X-11-5

Gregory, J.E., Paxton, S.J., \& Brozovic, A.M. (2010). Pressure to eat and restriction are associated with child eating behaviors and maternal concern about child weight, but 
not child body mass index, in 2 to 4-year-old children. Appetite, 54, 550-556. https://doi.org/10.1016/j.appet.2010.02.013

Harris, H.H., Fildes, A., Mallan, K.M., \& Llewellyn, C.H. (2016). Maternal feeding practices and fussy eating in toddlerhood: A discordant twin analysis. International Journal of Behavioral Nutrition and Physical Activity, 13 (81). https://doi.org/10.1186/s12966016-0408-4

Haszard, J.J., Skidmore, P.M.L., Williams, S.M., \& Taylor, R.W. (2014). Associations between parental feeding practices, problem food behaviours, and dietary intake in New Zealand overweight children aged 4-8 years. Public Health Nutrition, 18 (6), 1036-1043. https://doi.org/10.1017/S1368980014001256

Hendy, H., Williams, K., \& Camise, T. (2013). Reduce child obesity: A guide to using the kids choice program in school and at home. R\&L Education.

Horodynski, M.A., Stommel, M., Brophy-Herb, H., Xie, Y., \& Weatherspoon, L. (2010). Population at risk across the lifespan: case studies: low-income African American and Non-Hispanic white mother's self-efficacy, "picky eater" perception, and toddler, fruit and vegetable consumption. Public Health Nursing, 27 (5), 408-417.

van der Horst, K. (2012). Overcoming picky eating: Eating enjoyment as a central aspect of $\begin{array}{llll}\text { children's eating } \quad \text { behaviors. } & \text { Appetite, }\end{array}$ https://doi.org/10.1016/j.appet.2011.12.019

van der Horst, K., Eldridge, A., Deming, D., \& Reidy, K. (2014). Caregiver's perceptions about picky eating: Associations with texture acceptance and food intake. FASEB Journal, 28 (1).

Jansen, P.W., de Barse, L.M., Jaddoe, V.W.V., Verhulst, F.C., Franco, O.H., \& Tiemeier, H. (2017). Bi-directional associations between child fussy eating and parent's pressure to eat: Who influences whom? Psychology and Behavior, 176, 101-106. https://doi.org/10.1016/j.physbeh.2017.02.015

Jordan, A.A., Appugliese, D.P., Miller, A.L., Lumeng, J.C., Rosenblum, K.L., \& Pesch, M.H. (2020). Maternal prompting types and child vegetable intake: Exploring the moderating role of picky eating. Appetite, 146. https://doi.org/10.1016/j.appet.2019.104518

Luchini, V., Musaad, S., Lee, S.Y., \& Donovan, S.M. (2017). Observed differences in child picky eating behavior between home and childcare locations. Appetite, 116, 123-131. https://doi.org/10.1016/j.appet.2017.04.021

Lumeng, J.C., Miller, A.L., Appugliese, D., Rosenblum, K., \& Kaciroti, N. (2018). Picky eating, pressuring feeding, and growth in toddlers. Appetite, 123, 299-305. https://doi.org/10.1016/j.appet.2017.12.020

Machado, B.C., Dias, P., Lima, V.S., Campos, J., Goncalves, S. (2015). Prevalence and correlates of picky eating in preschool-aged children: A population-based study. Eating Behaviors, 22, 16-21. https://doi.org/10.1016/j.eatbeh.2016.03.035

Mascola, A.J., Bryson, S.W., Agras, W.S. (2010). Picky eating during childhood: A longitudinal study to age 11 years. Eating Behaviors, 11 (4), 253-257.

Mash, E.J., \& Wolfe, D.A. (2013). Abnormal Child Psychology 5th Edition. Cengage.

Mash, E.J., \& Wolfe, D.A. (2016). Abnormal Child Psychology 6th Edition. Cengage.

Papalila, D.E. \& Martorell, G. (2015). Experience human development $13^{\text {th }}$ edition. McGrawHill Education.

Rowell, K. \& Mcglothlin, J. (2015). Helping your child with extreme picky eating. New Harbinger Publication. 
Sandvik, P., Ek, A., Somaraki, M., Hammar, U., Eli, K., \& Nowicka, P. (2018). Picky eating in Swedish preschoolers of different weight status: Application of two new screening cut-offs. International Journal of Behavioral Nutrition and Physical Activity, 15 (74). https://doi.org/10.1186/s12966-018-0706-0

Shloim, N., Edelson, L.R., Martin, N., \& Hetherington, M.M. (2015). Parenting style, feeding style, feeding practices, and weight status in 4-12 years old children: A systematic review of the literature. Frontiers in Psychology, 6,1849. https://doi.org/10.3389/fpsyg.2015.01849

Taylor, C.M., Wernimont, S.M., Northstone, K., Emmet, P.M. (2015). Picky/ fussy eating in children: Review of definitions, assessment, prevalence, and dietary intakes. Appetite, 95, 349-359. https://doi.org/10.1016/j.appet.2015.07.026

Tharner, A., Jansen, P.W., Kiefte-de Jong, J.C., Moll, H.A., van der Ende, J., Jaddoe, V.W.V., Hofman, A., Tiemeier, H., \& Franco, O.H. (2014). Toward an operative diagnosis of fussy/picky eating: a latent profile approach in a population-based cohort. International Journal of Behavioral Nutrition and Physical Activity, 11, 14. https://doi.org/10.1186/1479-5868-11-14

Tharner, A., Jansen, P.W., Kiefte-de Jong, J.C., Moll, H.A., Hofman, A., Jaddoe, V.W.V., Tiemeier, H., \& Franco, O.H. (2014). Toward an operative diagnosis of fussy/picky eating: a latent profile approach in a population (2015). Bidirectional associations between fussy eating and functional constipation in preschool children. Journal of Pediatrics, 166, 91-96. https://doi.org/10.1016/j.jpeds.2014.09.028

Trofholz, A.C., Schulte, A.K., \& Berge, J.M. (2017). How parents describe picky eating and its impact on family meals: A qualitative analysis. Appetite, 110, 36-43. https://doi.org/10.1016/j.appet.2016.11.027

Vaughn, A.E., Ward, D.S., Fisher, J.O., Faith, M.S., Hughes, S.O., Kremers, S.P.J., MusherEizenman, D.R., O'Connor, T.M., Patrick, H., \& Power, T.G. (2016). Fundamental constructs in food parenting practices: a content map to guide future research. Nutrition Reviews, 72 (2), 98-117. https://doi.org/10.1093/nutrit/nuv061

Wright, C.M., Parkinson, K.N., Shipton, D., \& Drewett, R.F. (2007). How do toddler eating problem relate to their eating behavior, food preferences, and growth? Pediatrics, 120, 1069-1075. 